logy of parkinsonism, he suggests that some of these abnormal movement disorders are due to over-stimulation of some dopaminergic receptors in the corpus striatum. Inevitably, much of the section is hypothetical, but the clinical, pharmacological and other evidence is marshalled in a convincing way to support the author's tentative conclusions. The hypotheses that $\mathrm{Dr}$ Klawans, and many other workers in the field, have put forward to explain abnormal movement disorders on a biochemical basis provide a framework for further research. Time will tell whether they are true or not, but meanwhile Dr Klawans's monograph provides a useful statement of the present evidence and will be of value to the many clinical and basic research workers interested in this expanding field of neurology.

C. D. MARSDEN

\section{Solid State Theory}

Theoretical Solid State Physics. By Albert Haug. Vol. 1. Pp. xiv +497. (Pergamon: Oxford and New York, May 1972.) $£ 7$.

Theoretical Solid State Physics. By Albert Haug. Translated by H. S. H. Massey. Edited by D. ter Haar. Vol. 2. Pp. xiii +355 . (Pergamon: Oxford and New York, August 1972.) $£ 6$.

THESE volumes are translations from the German of the original editions, of which volume 1 was published in Vienna in 1964 and volume 2 in 1970. The level of treatment is suitable for a student who has completed a first degree in physics. It was the aim of the author "to make the derivations so detailed that they could be understood without any additional calculations". This aim, it must be said, is on the whole achieved. Formal mathematical derivations are set out at length, to the extent that the summation of a geometric series may be broken down into several steps. One can only presume that it was for this reason the book was thought to be sufficiently different from existing texts to merit translation. The market is, after all, well supplied with introductions to solid state theory.

The intended scope of the volumes is perhaps indicated by a quotation from the foreword to volume 2: "We are thus dealing with a closed body of solid state physics which will not be rendered superfluous by yet newer developments, and this state is represented by the present work". Volume 1 covers the elementary theory of electrons in a perfect lattice, including Wannier functions but with only a sketch of methods of band-structure calculation, the Bohm and Pines theory of the interacting electron gas, simple treatments of the magnetic and dielectric properties of solids, and the elemen- tary theory of lattice vibrations. There is some emphasis on one-dimensional models. Volume 2 treats the electronlattice interaction, with an account of Bardeen's classic 1937 calculation, gives a rather formal account of transport phenomena based on the Boltzmann equation, and concludes with sections on semiconductor theory and luminescence.

Even in 1964, however, volume 1 might have been thought a little out of touch. (The only updating I can find is a footnote on page 177.) Volume 2 virtually ignores the insights and results that have been gained in the past decade. A student studying these volumes in isolation would gain the impression that it is almost impossible to make calculations in solid state physics with more than order of magnitude accuracy. It was, to take one example, already clear in 1964 that the concept of a screened model potential was a valuable aid in understanding the properties of simple metals, and making realistic calculations. The Bohm and Pines theory, and the Bardeen theory of the electron-ion interaction, are landmarks in the development of solid state theory, but the equivalent dielectric constant formalism is at least as easy to present, and has proved far more convenient in practice.

It is impossible to recommend these volumes as an introduction to the current literature of the solid state. They have, perhaps, some value as a reference work for students who have local difficulties in the mathematical derivations of elementary solid state theory.

\section{A. GREENWOOD}

\section{Geochemistry}

Geochemical Exploration 1972. Edited by M. J. Jones. (Proceedings of the Fourth International Geochemical Exploration Symposium held in London April 17-20, 1972 . Organized by the Institution of Mining and Metallurgy. Pp. xiv +458 . (The Institution of Mining and Metallurgy: London, February 1973.) $£ 12$; $\$ 30$.

THIS volume contains thirty-seven papers read at the Fourth International Geochemical Exploration Symposium held in London in April 1972. They are the work of forty-four authors from twelve nations and encompass a great number of the more important aspects of the subject, though, whilst including some short case histories, they are mainly concerned with the results of research into new and developing fields. The publishers are to be congratulated on the speed with which they have produced this volume. Apart from a few over-reduced and unreadable figures, the reproduction and legibility of figures both black-and-white and coloured are of a high order.
The volume demonstrates the rapid advances being made in applied geochemistry and includes a number of "firsts". One is a paper describing anomalous metal concentrations in snow overlying ground containing sulphide ore. Another is a novel account of geological mapping and geochemical sampling using light aircraft. The methods of scooping up rock and sediment samples during flight at only a metre or so above ground level are enough to make the reader's hair stand on end. Though not quite a "first", the paper by Dr Allan and others on the use of lake sediments in reconnaissance exploration breaks fresh ground in sampling techniques. Other papers concerned with sampling in the more usual media of soil, stream sediment and rock samples cover such diverse topics as the use of gold as a pathfinder element for porphyry copper deposits, trace element patterns as a guide to ore-bearing granites, sulphur and nickel concentrations in serpentinites as a guide to mineralized areas and the use of bedrock geochemistry in regional surveys.

A landmark in the study of secondary dispersion is Professor Govett's paper in which he describes laboratory tank experiments to support the view that significant differential secondary rearrangement of metals in soils and rocks related to sulphide ore bodies may occur under the inffuence of electrical potentials. This could lead to new approaches to exploration through various electrophysical and chemical measurements which would allow a deeper penetration of thick transported overburden-a topic dealt with in other papers. Statistical analysis of geochemical data is given prominence in six papers and is applied in many others. Cluster analysis, pattern r $2 \operatorname{cog}$ nition and automated colour-mapping are included.

Mercury as a pathfinder element has attracted much interest in recent years, and it is interesting to read that studies of mercury in rock samples from an Irish deposit indicate that mercuric sulphide may be a better guide to ore than total mercury values. The use of gases is described in two contributions from the USSR which inter alia demonstrate their value in mapping fracture zones.

About one third of the papers deal with new techniques and instrumentation. These include the measurement of atmospheric mercury with a Zeeman spectrometer, a microwave-induced argon plasma emission system for trace analysis, fission track radiography, neutron activation analysis, in situ measurement of $\mathrm{Eh}$ and $\mathrm{pH}$ in diamond drill holes and the use of the ion-sensitive fluoride electrode.

A. M. Evans 